\title{
Terahertz Metamaterial-Based Microbolometers Fabricated by Conventional MEMS
}

\author{
Tianhong Ao, Xiangdong Xu*, Yu Gu, Zhegeng Chen, Yadong Jiang*, Xinrong Li, \\ Yuxiang Lian, Fu Wang, Qiong He
}

State Key Laboratory of Electronic Thin Films and Integrated Devices, School of Optoelectronic Information, University of Electronic Science and Technology of China (UESTC), Chengdu, China

Email: tianhong_ao@hotmail.com, “xdxu@uestc.edu.cn, jiangyd@uestc.edu.cn

Received 16 June 2016; accepted 22 August 2016; published 25 August 2016

\begin{abstract}
$37 \mu \mathrm{m} \times 37 \mu \mathrm{m}$ array of metamaterial-based microbolometers was designed and successfully fabricated by conventional MEMS technology. FTIR measurements reveal that the as-designed microbolometers exhibit a high absorption of $\sim 31.5 \%$ at $3.93 \mathrm{THz}$. In contrast, no response can be detected from those microbolometers without metamaterials. The experimental results have been confirmed by simulations.
\end{abstract}

\section{Keywords}

Metamaterial, Absorber, MEMS, THz

\section{Introduction}

Recently, metamaterials (MMs) have attracted great attention owing to their outstanding electromagnetic properties as artificial functional materials [1]. A significant superiority of MMs over natural materials is that MMs can easily achieve desirable electromagnetic responses [2]. Applications of MMs in terahertz (THz) regime, a band range from $0.1 \mathrm{THz}$ to $10 \mathrm{THz}$, provide new option to $\mathrm{THz}$ system including $\mathrm{THz}$ source, propagation, and detecting [3]-[5]. It is reported that well-designed MMs with Metal/Dielectric/Metal (MDM) sandwich structure can perform as perfect absorbers with nearly $100 \%$ absorption [6] [7]. On the other hand, the development of uncooled $\mathrm{THz}$ detectors is practically challenged, largely due to rather weak $\mathrm{THz}$ absorption of common functional materials and devices [8]. In order to solve this problem, we tried to fabricate MMs absorbers on microbolometers by conventional micro-electromechanical systems (MEMS) technology.

Generally, complete microbolometers consist of optical windows, read circuits, electrodes, thermistors, etc. In order to simplify the investigation, we focused on the mechanical and $\mathrm{THz}$ responses of the microbolometers, whose results would rightly reflect the complete devices. In this work, square-shaped MDM metamaterial absorbers were designed and fabricated on conventional microbolometers.

\footnotetext{
${ }^{*}$ Corresponding authors.
} 


\section{Process for Fabrication of MM-Based Microbolometers}

The fabrication process is illustrated in Figure 1(a). In step 1, a $2 \mu \mathrm{m}$-thick polyimide was spun on a Si wafer. Apertures were etched to be open for follow-up piers. Then, a $300 \mathrm{~nm}$-thick $\mathrm{SiN}_{x}$ film was deposited by plasmaenhanced chemical vapor deposition (PECVD) and serves as supporting layer for microbolometers. In step 2, a $100 \mathrm{~nm}$-thick bottom aluminum (Al) film was deposited by electron beam evaporation. Subsequently, another $900 \mathrm{~nm}$ dielectric $\mathrm{SiN}_{x}$ film was deposited by PECVD again, serving as dielectric for metamaterials. After that, square-shaped dielectric layer was etched. In step 3, upper square Al was deposited and etched. At the same time, the bottom square $\mathrm{Al}$ was corroded. Finally, in step 4, microbridges were patterned. After the sacrificial layer polyimide had been released, MM-based microbolometers were yielded. SEM image in Figure 1(b) confirms successful fabrication of MM-based microbolometers by MEMS.

The MM-based microbolometers were fabricated as $37 \mu \mathrm{m} \times 37 \mu \mathrm{m}$ array. Figure 2(a) shows the model of microbolometer structure, where $a, b, a_{1}$, and $b_{1}$ are $21 \mu \mathrm{m}, 18 \mu \mathrm{m}, 18 \mu \mathrm{m}$, and $15 \mu \mathrm{m}$, respectively. The thicknesses of $\mathrm{SiN}_{x}$ films as supporting and dielectric layers are described above. Firstly, we evaluated the mechanical stability of the as-designed microbolometers by ANSYS software. This was performed by simulating the effects of a residual stress $(+300 \mathrm{MPa})$ on the deformation of bolometers. As shown in Figure 2(b), the stress is concentrated on the corners of the microbridge, and thus the microbridge is moved for $\sim 0.76 \mu \mathrm{m}$. It is worth noting that such deformation $(\sim 0.76 \mu \mathrm{m})$ is not bad enough to damage the microbridge, as proved by Figure 1(b).

\section{Simulation and Measurement Results}

In this work, we pay special attention to the responses of the microbolometers in THz region. The THz responses of the MM-based microbolometers were first simulated by CST software. In the simulations, the refractive index ( $n$, and $\mathrm{n}=\sqrt{\varepsilon}$ ) of $\mathrm{SiN}_{x}$ is 1.98 , and the conductivity of aluminum is $4.56 \times 10^{7} \mathrm{~S} / \mathrm{m}$. Simulations reveal that the absorption of the MM-based microbolometers is $\sim 43.3 \%$ at $3.97 \mathrm{THz}$ (Figure 3, blue line), but almost zero for those microbolometers without MMs (Figure 3, black line). In optical experiment, transmittance $T$ and reflectance $R$ can be measured, and the absorption A derives from $A=1-\mathrm{T}-\mathrm{R}$. It is worth noting that absorption of $\sim 31.5 \%$ at a central frequency of $3.93 \mathrm{THz}$ was experimentally measured by Fourier transform infrared spectroscopy (FTIR) (Figure 3, red line). Such THz absorption ( 31.5\%) is 1 - 2 order magnitude higher than those of the conventional microbomometers without MMs. Clearly, the experimental measurement agrees well with the simulated result (Figure 3), both of which demonstrate that the THz absorption of the microbolometer indeed can be significantly enhanced by the additional MMs. Such MM-based microbolometers with high $\mathrm{THz}$ absorption hold great potential for applications in $\mathrm{THz}$ detectors.

Step 1. 300nm $\operatorname{SiN}_{x}$ was first deposited on polyimide layer

Step 2. $100 \mathrm{~nm}$ bottom $\mathrm{Al}$ and $900 \mathrm{~nm}$ dielectric $\mathrm{SiN}_{x}$ layer were sequentially deposited, then the $\mathrm{SiN}_{x}$ was etched as square-shape

Step 3. 100nm upper Al was deposited and etched

Step 4. the pattern of microbolometer was etched

(a)

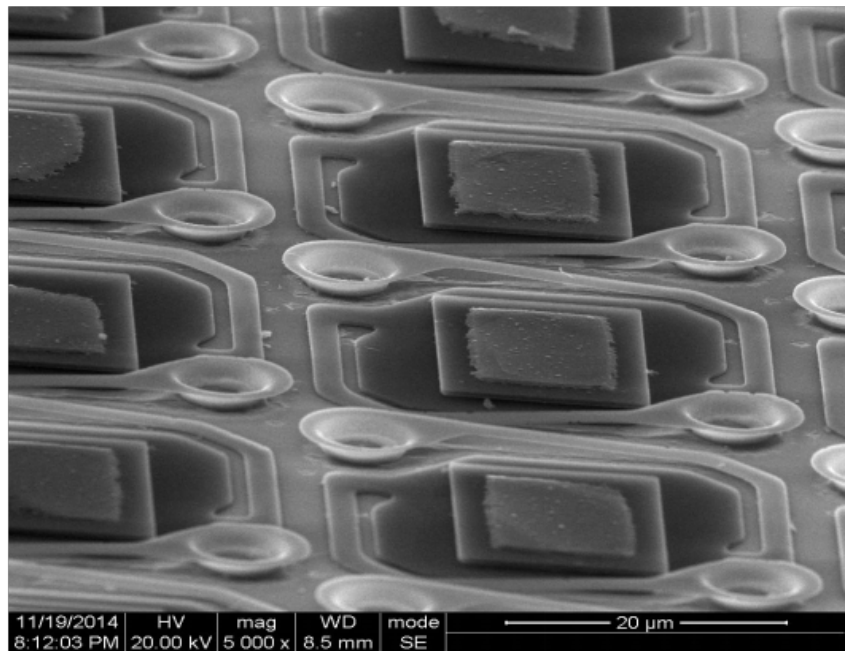

(b)

Figure 1. (a) The left indication shows the process steps for fabrication of MM-based microbolometers, the right pictures are the optical images for the sample after each steps, (b) the top view of SEM image of the as-fabricated array. 


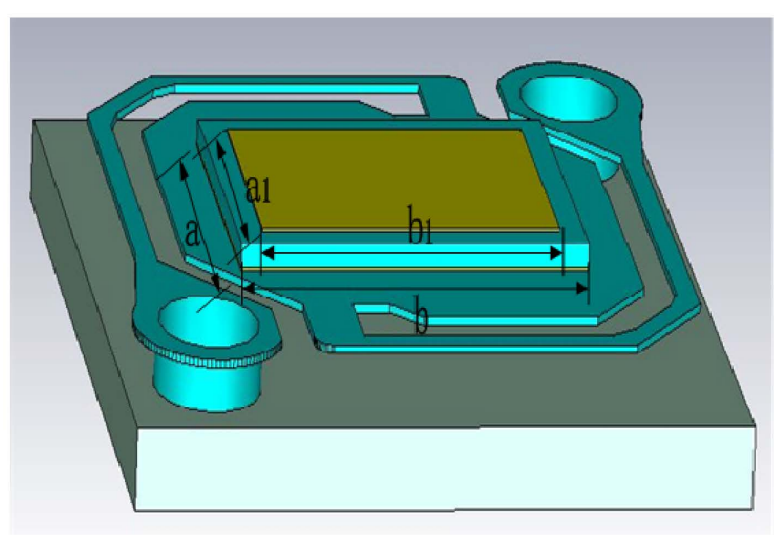

(a)

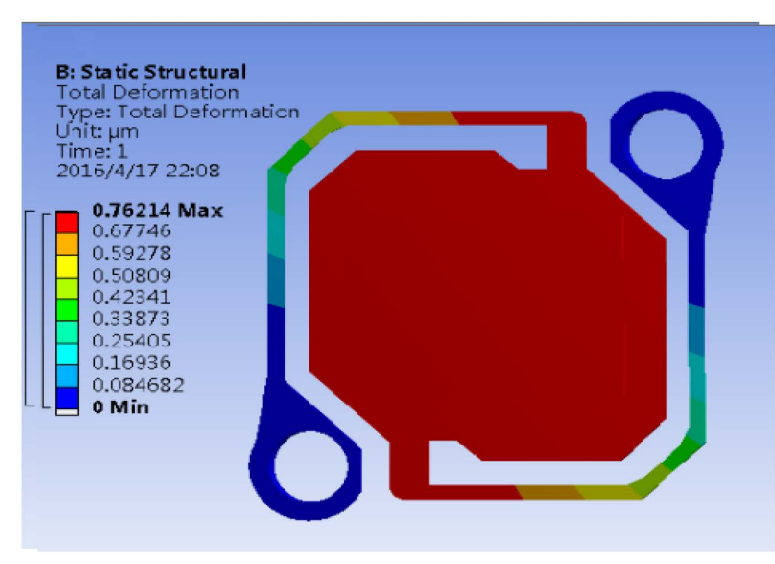

(b)

Figure 2. (a) The model of microbolometers in simulation; (b) simulated deformation of the microbridge.

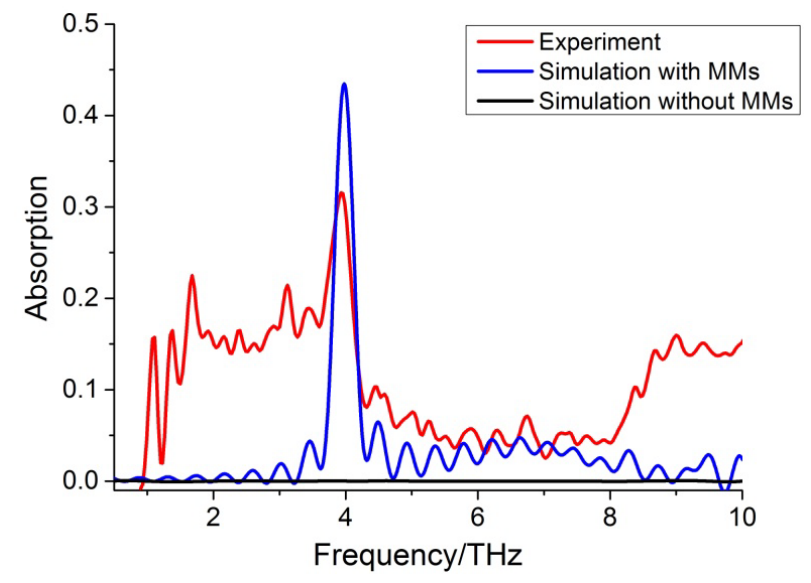

Figure 3. Experimental (FTIR) and simulated results of the microbolometers with and without MMs.

\section{Conclusion}

In summary, MM-based microbolometers were designed and successfully fabricated by conventional MEMS. Both simulation and experimental measurement demonstrate that the $\mathrm{THz}$ absorption of the microbolometers can be significantly enhanced by the additional MM absorbers. Our results will be helpful for the development of novel and efficient microbolometers for uncooled THz imaging.

\section{Acknowledgements}

We acknowledge the financial support of the National Natural Science Foundation of China (NSFC 61071032, 61377063, 61235006, 61421002).

\section{References}

[1] Shalaev, V.M. (2007) Optical Negative-Index Metamaterials. Nat. Photonics, 1, 41-48. http://dx.doi.org/10.1038/nphoton.2006.49

[2] Liu, N., Guo, H.C., Fu, L.W., Kaiser, S., Schweizer, H. and Giessen, H. (2008) Three-Dimensional Photonic Metamaterials at Optical Frequencies. Nat. Mater., 7, 31-37. http://dx.doi.org/10.1038/nmat2072

[3] Luo, L., Chatzakis, I., Wang, J.G., Niesler, F.B.P., Wegener, M., Koschny, T. and Soukoulis, C.M. (2014) Broadband Terahertz Generation from Metamaterials. Nat. Commun., 5, 1-6. http://dx.doi.org/10.1038/ncomms4055

[4] Chen, H.T., Padilla, W.J., Zide, J.M.O., Bank, S.R., Gossard, A.C., Taylor, A.J. and Averitt, R.D. (2007) Ultrafast Optical Switching of Terahertz Metamaterials Fabricated on ErAs/GaAs Nanoisland Superlattices. Opt. Lett., 32, 
1620-1622. http://dx.doi.org/10.1364/OL.32.001620

[5] Park, S.J., Hong, J.T., Choi, S.J., Kim, H.S., Park, W.K., Han, S.T., Park, J.Y., Lee, S., Kim, D.S. and Ahn, Y.H. (2014) Detection of Microorganisms Using Terahertz Metamaterials. Sci. Rep., 4, 1-7. http://dx.doi.org/10.1038/srep04988

[6] Landy, N.I., Sajuyigbe, S.J., Mock, J., Smith, D.R. and Padilla, W.J. (2008) Perfect Metamaterial Absorber. Phys. Rev. Lett, 100, 207402. http://dx.doi.org/10.1103/PhysRevLett.100.207402

[7] Hu, T., Landy, N.I., Bingham, C.M., Zhang, X., Averitt, R.D. and Padilla, W.J. (2008) A Metamaterial Absorber for the Terahertz Regime: Design, Fabrication and Characterization. Opt. Express, 16, 7181-7188. http://dx.doi.org/10.1364/OE.16.007181

[8] Lee, A.W. and Hu, Q. (2005) Real-Time, Continuous-Wave Terahertz Imaging by Use of a Microbolometer FocalPlane Array. Opt. Lett., 30, 2563-2565. http://dx.doi.org/10.1364/OL.30.002563

\section{Submit or recommend next manuscript to SCIRP and we will provide best service for you:}

Accepting pre-submission inquiries through Email, Facebook, Linkedin, Twitter, etc A wide selection of journals (inclusive of 9 subjects, more than 200 journals)

Providing a 24-hour high-quality service

User-friendly online submission system

Fair and swift peer-review system

Efficient typesetting and proofreading procedure

Display of the result of downloads and visits, as well as the number of cited articles

Maximum dissemination of your research work

Submit your manuscript at: http://papersubmission.scirp.org/ 